\title{
Atopic eczema: its impact on the family and financial cost
}

\author{
John C Su, Andrew S Kemp, George A Varigos, Terence M Nolan
}

\begin{abstract}
Objective-To evaluate the impact of childhood atopic eczema on families and assess the personal financial cost of its management.

Design-Cross sectional survey.

Setting-Paediatric dermatology and paediatric diabetology outpatient clinics. Patients-Parents of 48 randomly selected children with atopic eczema and 46 with insulin dependent diabetes mellitus.

Main outcome measures-The impact on family score, the reported cost of relevant medical treatments, medical consultations, relevant hospitalisation, and income loss.

Results-Families of children with moderate or severe atopic eczema had a significantly higher impact on family score than families of diabetic children. A conservative estimate of the annual personal financial cost of managing mild, moderate, and severe eczema was Aus $\$ 330,818$, and 1255 , respectively. The financial cost to the community for the management of atopic eczema in the study groups was greater. The personal financial cost of managing eczema was greater than for asthma.
\end{abstract}

Conclusion-Childhood atopic eczema has a profound impact on the social, personal, emotional, and financial perspectives of families.

(Arch Dis Child 1997;76:159-162)

Keywords: atopic dermatitis; impact on family; financial cost.

Atopic eczema is a common paediatric dermatosis. The incidence of this disease has increased, like asthma, since the 1950s and its prevalence is higher in urban than in rural settings. ${ }^{1}$ The onset is in infancy in $60 \%$ of patients and before 5 years of age in $90 \%$. The disease continues beyond infancy in about one third of infants and affects one third of these children as adolescents. ${ }^{2}$ Atopic eczema is responsible for most paediatric dermatological admissions, is the single most common skin condition in children less than 11 years of age, and it is also an important cause of morbidity when affecting adults. ${ }^{3}$ Some $25-50 \%$ of children with eczema develop asthma and 30\% develop allergic rhinitis. A recent conservative estimate of the annual total national cost for the treatment of childhood eczema in the United States was $\$ 364$ million. $^{4}$ The personal and family financial costs of caring for children with atopic dermatitis, however, have not been studied.

The aim of this study was to evaluate the impact of atopic eczema on families and to assess the financial cost of caring for children with atopic eczema of varying severity. We compared the impact of eczema on families with that of diabetes mellitus, a disease perceived as emotionally stressful because of the need for regular injections, blood sugar testing, dietary restrictions, and its potential for acute and chronic life threatening complications.

\section{Methods}

The target population comprised infants and children presenting with atopic dermatitis to the dermatology clinic at the Royal Children's Hospital between March and August 1995 and their families. Forty eight children (30 boys) aged from 4 months to 15 years (mean (SD) age 4.5 (4.2) years) were selected sequentially. Patients were graded according to severity using the system described by Rajka and Langeland. ${ }^{5}$ Eczema was categorised as mild, moderate, or severe by assessing the percentage of body surface involved, the course of the illness, and intensity of itching. Scoring was carried out by a dermatology registrar or consultant. Parents were directly questioned regarding the presence of other relevant medical conditions in the child's history.

The impact on family questionnaire of Stein and Riessman was instituted. ${ }^{6}$ This questionnaire, which determines the effects of a chronic illness on parents and families, has been used to assess the impact of conditions such as spina bifida, ventilator dependence, post-traumatic brain injury, and behavioural disturbance..$^{7-10}$ It is based on four subscales assessing perceived (1) financial burden; (2) familial/social impact; (3) personal strain; and (4) mastery. The first subscale contains four statements, for example 'My child's eczema is causing financial problems for the family'. The second subscale contains nine statements assessing social effects of eczema, for example 'People in the neighbourhood treat us differently because of my child's eczema'. The third subscale has six statements relating to the personal stress imposed by eczema on the parent, for example 'Nobody understands the burden I carry'. The final subscale contains positively phrased statements to assess the positive effects of the child's eczema on the parent's feelings of control in his or her life, for example 'Learning to manage my child's eczema has made me feel better about myself '. The parent's response is given as a 
Table 1 Impact on family scores comparing diabetes and eczema of all ages

\begin{tabular}{lll}
\hline Condition & Impact on family score $(95 \%$ CI) & p Value eczema v diabetes \\
\hline Diabetes $(\mathrm{n}=46)$ & $1.85(1.7$ to 2.0$)$ & \\
All patients with eczema $(\mathrm{n}=48)$ & $2.25(2.1$ to 2.4$)$ & 0.0012 \\
Severe eczema $(\mathrm{n}=10)$ & $2.61(2.3$ to 2.9$)$ & 0.0002 \\
Moderate eczema $(\mathrm{n}=20)$ & $2.31(2.0$ to 2.6$)$ & 0.0032 \\
Mild eczema $(\mathrm{n}=18)$ & $1.97(1.7$ to 2.2$)$ & 0.41 \\
\hline
\end{tabular}

$\mathrm{CI}=$ confidence interval.

The impact on family score is given as a number between 1 and 4 . A higher score represents a higher impact.

Table 2 Impact on family scores after adjustment for age differences

\begin{tabular}{lll}
\hline Condition & $\begin{array}{l}\text { Impact on family score (age } \\
\text { adjusted) }(95 \% \text { CI) }\end{array}$ & $\begin{array}{l}\text { p Value eczema v diabetes } \\
\text { (age adjusted) }\end{array}$ \\
\hline Severe eczema $(\mathrm{n}=10)$ & $2.60(2.3$ to 2.9$)$ & 0.001 \\
Moderate eczema $(\mathrm{n}=20)$ & $2.23(2.0$ to 2.5$)$ & 0.094 \\
Mild eczema $(\mathrm{n}=18)$ & $1.87(1.6$ to 2.2$)$ & 0.285 \\
Diabetes $(\mathrm{n}=46)$ & $1.92(1.8$ to 2.1$)$ & \\
\hline
\end{tabular}

$\mathrm{CI}=$ confidence interval

The impact on family score is given as a number between 1 and 4 . A higher score represents a higher impact.

number from 1 to 4 , where 1 represents strong agreement, 2 predominant agreement, 3 weak partial agreement, and 4 strong disagreement. The fourth subscale is reverse coded, so that it is compatible with the other subscales to calculate a final score where a low score corresponds to a high impact. This score is then inverted so that a high score is equivalent to a high impact. The questionairre was administered by a single researcher (JCS).

A control population was formed by 46 consecutive children ( 21 boys) with insulin dependent diabetes from the diabetes clinic at the Royal Children's Hospital. This is a representative sample of diabetic children as almost all children within and around the metropolitan region of Melbourne are managed at this hospital. ${ }^{11}$

The mean impact on family scores was compared by two sample $t$ test analysis. Analysis of covariance was performed with age as a covariate to assess the difference between the groups after adjusting for age.

Financial costs were assessed by a questionnaire using four variables: (1) the cost of medication and related expenses during the past 12 months; (2) the number of visits to health professionals during the past 12 months; (3) the number of hospital admission days in the past year; and (4) the indirect costs contributing to income loss. Indirect costs were: (1) the number of days taken off work to care for the child's eczema or to bring the child for management of eczema; (2) the effect of the eczema on their employment; and (3) the average number of hours a day used for treatment averaged over three months. Questions were directed specifically to the cost of eczema specific treatment and should not have been influenced by coexistent illnesses such as asthma. Where a range was given, the lower estimate was used. Income loss was estimated as that lost for time off work. Lower estimates were also used-that is, annual incomes of more than Aus $\$ 30000$ were estimated as Aus $\$ 30000$, incomes of between Aus $\$ 20000$ and Aus $\$ 30000$ as Aus $\$ 20000$, and incomes of less than Aus $\$ 20000$ as Aus $\$ 10000$.
Another item that was evaluated was the number of hours lost in sleep averaged over three months from observations and records.

The presence of financial support was ascertained. Financial demographic data obtained included parental employment status, parental education levels, home ownership, and car ownership.

\section{Results}

Of the 48 children with atopic dermatitis (mean (range) age 4.5 (0.3-15) years), 18 were graded as mild in severity (mean (range) age 3.5 (0.3-14) years), 20 as moderate (mean (range) age $4.2(0.3-11$ years) and 10 as severe (mean (range) age 6.6 (0.6-15) years). The diabetic children's ages ranged from 1 to 17 years (mean age 10.2 years).

\section{IMPACT ON FAMILY SCORES}

Table 1 shows the scores for families of children with eczema compared with those of diabetic children. All families of children with eczema had significantly higher impact scores than those of diabetic children. Categorisation of eczema into subgroups of different severity showed that moderate and severe eczema groups have significantly higher impact scores than those associated with diabetes, whereas the mild eczema group had equivalent scores. In addition, as the mean age of children with atopic eczema was less than the mean age of children with diabetes, we considered only children under the age of 6 years. There was still a significantly higher impact on family scores for children less than 6 years old with moderate or severe eczema, but not for those in the mild group, when compared with values for diabetic children (data not shown). For all individuals, analysis of covariance was performed to assess whether there was a significant difference between the groups after adjusting for age (table 2). Children with moderate or severe eczema had higher scores than those with diabetes after adjusting for age differences, maintaining significance for the severe but not the moderate group.

Non-financial costs included time used for treatment, sleep deprivation, and marital problems. The mean (SD) daily time used for treatment was 3 (2.8) hours for the severe group, 3 (1.7) hours for the moderate group, and 2 (1.5) hours for the mild group. Time spent in preventing children from scratching was excluded.

The mean (SD) hours of sleep lost by parents averaged 1 (1.9) hours for parents in the severe group, 2 (1.5) hours for the moderate group, and 1 (1.3) hours for the mild group. The mean (SD) sleep lost by children was 2 (2.1) hours for the severe group, 2 (1.4) hours for the moderate group, and 1 (1.1) hours for the mild group.

Six children were from single parent families, three of whom were in the severe group. Of these, one child's eczema was considered by the parents to be an important factor in their marital difficulties. The parents of a fourth child in the severe group were discussing separation at 
Table 3 Mean number of medical visits a year. Value in parentheses is $95 \%$ confidence interval; only upper bound shown as lower bound was zero in all

\begin{tabular}{llll}
\hline & Mild eczema & Moderate eczema & Severe eczema \\
\hline Total visits to doctors & $7.0(15)$ & $13.0(30)$ & $23.3(52)$ \\
General practitioner & $4.0(11)$ & $7.0(21)$ & $11.7(30)$ \\
Paediatrician & $0.5(2.4)$ & $2.8(13)$ & $1.6(8.5)$ \\
Allergist & $0.2(1.5)$ & $0.3(1.5)$ & $3.3(13)$ \\
Dermatologist & $2.7(6.5)$ & $3.2(9.6)$ & $6.4(16)$ \\
Admission time (days) & $1.2(5.7)$ & $3.4(10)$ & $6.5(19)$ \\
\hline
\end{tabular}

Table 4 Financial costs (Australian dollar) of eczema to the family. Value in parentheses is $95 \%$ confidence interval; only upper bound shown as lower bound was zero in all

\begin{tabular}{llll}
\hline & $\begin{array}{l}\text { Mild eczema } \\
(n=18)\end{array}$ & $\begin{array}{l}\text { Moderate eczema } \\
(n=20)\end{array}$ & $\begin{array}{l}\text { Severe eczema } \\
(n=10)\end{array}$ \\
\hline $\begin{array}{l}\text { Direct } \\
\text { Medications }\end{array}$ & $200(414)$ & $346(946)$ & $469(1035)$ \\
$\quad$ Dressings & $22(81)$ & $155(565)$ & $142(336)$ \\
$\quad$ Diet & 0 & $81(306)$ & $360(1373)$ \\
$\quad$ Naturopathy & $93(173)[\mathrm{n}=5]$ & $75(195)[\mathrm{n}=4]$ & $268(980)[\mathrm{n}=4]$ \\
$\quad$ Other & $235(731)[\mathrm{n}=5]$ & $479(942)[\mathrm{n}=8]$ & $147(341)[\mathrm{n}=10]$ \\
$\quad$ Consultations & 17 & 29 & 30 \\
$\begin{array}{l}\text { Indirect } \\
\quad \text { Time off work }\end{array}$ & 150 & 894 & 1290 \\
Total & 480 & 1712 & 2545 \\
\hline
\end{tabular}

the time of writing, primarily over issues relating to the child's eczema and related behavioural problems.

\section{COMMUNITY COSTS}

The mean number of medical consultations was higher for children with more severe disease (table 3). More than $50 \%$ of consultations were with general practitioners. At least $85 \%$ of medical consultation costs and $100 \%$ of public hospital admission costs in Australia are borne by the public health system. The annual cost to the community of medical consultations for each child in the mild, moderate and severe groups (calculated from the Medical Benefits Schedule book) was Aus $\$ 209$, 389 , and 642 , respectively. The annual cost to the community of hospitalisation for each child in these three groups was Aus $\$ 453,1523$, and 2912 , respectively.

\section{DIRECT FINANCIAL COSTS}

The mean annual cost of eczema was related to the severity of eczema (table 4 ). The total mean costs of medication, dressings, diet, other eczema management strategies, and medical consultations for the mild, moderate, and severe groups were Aus $\$ 330,818$, and 1255 , respectively. The major costs were for medication and dressings. Other management strategies included changing of carpets, purchase of dust mite free covers, and purchase of extra non-irritant clothing. Only eight of the 48 patients had cost incurring investigations during the year. These were not included in the cost calculations. One patient, however, estimated the cost of tests alone to be Aus $\$ 2000$. The cost of medical visits to the families was determined using the Medicare Benefits Schedule book, based on the minimum consultation fees. The cost of medical visits borne by the government was excluded. In addition to medical practitioners and naturopaths, two children attended Chinese herbalists, one attended an aromatherapist, and another attended an 'acupuncture laser therapist'. For comparison, an estimate of the cost for similar categories (medication, medical equipment, diet, consultations, and miscellany) for 22 diabetic children averaged Aus $\$ 444$ (data not shown).

Indirect costs are also related to the severity of eczema. Time off work to care for the child's eczema or to bring the child for eczema management was necessary for the parents of six of 18 children with mild disease, 12 of 20 with moderate disease, and seven of the 10 children with severe disease (table 3 ). Income loss was conservatively estimated for time off work (table 4). In addition, employment was reduced, ceased, or not started for a parent of six of the 10 patients in the severe group, six of the 20 patients in the moderate group, and one of the 18 patients in the mild group. This potential income loss was not estimated. One father was retrenched for taking too much time off work to bring his child for medical care. The cost and time for travelling were not determined. Of the total eczema sample group, 15 fathers and 13 mothers had been educated at university, or an equivalent institution. Of the 10 children with severe eczema, four were from families with an annual income of less than Aus $\$ 20000$ and the remainder had incomes exceeding Aus $\$ 30000$.

\section{Discussion}

Although atopic eczema is common, it is not generally perceived as an illness presenting major problems for individuals and families, or one requiring specialised supportive care. The 1989-90 national health survey conducted by the Australian Bureau of Statistics estimated that there were 297500 children less than 15 years of age with 'recent' eczema and 163700 with 'long term' eczema in Australia, which represented 8 and $4.4 \%$ of that population, respectively. ${ }^{12}$ Self reported data for chronic illnesses may underestimate the period prevalence. ${ }^{13}$ These values compare with about 2000 children under 15 with diabetes and 492200 children with 'long term' asthma. A more recent survey of 6-7 year olds has found the current prevalence of eczema in Australia to be $8.6 \% .^{14}$

The social, family, and emotional effects and personal financial costs of eczema have never been quantified. The impact on family scale of Stein and Riessman is designed to assess such effects. We found that the impact on family scores was higher in the moderate and severe eczema groups, but not the mild group when compared with scores for the type 1 diabetes group. After age adjustment to account for higher scores in families of younger children, this difference was still significant for the severe group. Our findings show the profound impact of this common disorder on families, a fact that we believe is underappreciated in view of the lack of support for families of children with eczema compared with that for families of children with diabetes or asthma. Although this hospital based study includes more patients in the moderate and severe groups than would be expected in the community, it is noteworthy that even in the mild group, the impact on 
family score was equivalent to that for children with insulin dependent diabetes.

A recent Australian study of asthmatic children suggested that the mean annual cost to a family of a child with asthma was Aus $\$ 212.48$, with 13.4 hours spent in treatment. ${ }^{15}$ For a child with asthma who had been admitted to hospital, it was Aus $\$ 884.34$, with 153 hours spent in treatment. For a child with diabetes in our study it was Aus $\$ 444$. This value compares with the estimate of Aus $\$ 467$ given by the Juvenile Diabetes Foundation of Australia for similar categories, although they allowed a further Aus $\$ 1000$ for dietary expenses. The cost of asthma and diabetes may be compared with the cost of managing eczema. The mean annual, direct, out of pocket cost of treatment for a family of a child with mild, moderate, and severe childhood eczema was Aus $\$ 330,818$, and 1255 , respectively. In addition, there are considerable costs to the community, namely hospitalisation, medical consultations, and medications. Our direct cost results did not include the costs of child care and insurance, which were included in the asthma cost analysis study previously quoted. Our data suggest that direct financial cost in the care of a child with moderate or severe eczema is substantially higher than for the average child with asthma. Likewise, the direct cost in caring for a child with severe eczema is higher than for a child who has required hospitalisation for asthma in the preceding year. The direct financial cost of diabetes is similar to that of eczema. Thus, the higher impact on family scores in more severe eczema as compared to diabetes, indicates pronounced stress, other than financial, on families with children suffering with eczema.

Apart from the direct financial costs, our study revealed several factors that may have contributed to the higher impact on family scores, such as sleep deprivation, time taken to care for the child, and interruption to employment with its attendant indirect financial costs. Between two and three hours each day was generally spent treating eczema and an average of one to two hours of sleep each night was interrupted. Time off work arising from hospital visits and caring for the child at home was substantial in all groups, although unemployability because of eczema seemed to affect only the moderate and severe groups. This may cost the community in the form of lost productivity and sick leave, or cost the individual as loss of income. Time off work because of a child's eczema was conservatively estimated to cost a family from the mild, moderate, and severe groups an additional Aus $\$ 150,894$, and 1290 each year, respectively. This compared with Aus $\$ 270$ for the diabetes group. The cost of unemployment resulting from the child's eczema and transport costs relating to eczema treatment were not assessed. In addition to cost, there are many other potential reasons for the high impact of eczema on families, including parental feelings of guilt, effects of sleep deprivation on parents and children, behavioural and maladjustment problems, sibling rivalry, as well as effects of eczema on the child's psychological development, childhood self esteem, and socialisation skills. Many parents reported that the time the child spent scratching was an important concern.

Management of atopic eczema in children is potentially complex and costly, often requiring a well planned multidisciplinary approach for optimal care. As detailed in the study, there are many potential complications that affect the quality of life in children and families. Foundations and support services devoted to care and research exist in Australia for asthma, diabetes mellitus, and several less common conditions. There is a real need for doctors and administrators to recognise that eczema is not necessarily a minor skin disorder, but a major handicap with a considerable personal, social, and financial burden on the family.

We thank Dr George Werther for allowing us access to patients from the paediatric diabetology clinic.

1 Hanifin JM. Epidemiology of atopic dermatitis. Monogr Allergy 1987;21:116-31.

2 Weston WL, Lane AT. Color textbook of pediatric dermatology. St Louis: Mosby-Yearbook, 1991.

3 Hanifin JM, Rajka G. Diagnostic features of atopic dermatitis. Acta Derm Venereol Suppl (Stockh) 1980;92:44-7.

4 Lapidus CS, Schwarz DF, Honig PJ. Atopic dermatitis in children: who cares? Who pays? F Am Acad Dermatol 1993; 28:699-703.

5 Rajka G, Langeland T. Grading the severity of atopic dermatitis. Acta Derm Venereol Suppl (Stockh) 1989;144:13-

6 Stein REK, Riessman CK. The development of an impacton-family scale: preliminary findings. Med Care 1980;18

7 Loebig M. Mothers' assessment of the impact of children with spina bifida on the family. Matern Child Nurs F 1990; 19:251-64.

8 Quint RD, Chesterman E, Crain LS, Winkleby M, Bryce WT. Home care for ventilator-dependent children. Psychological impact on the family. Am F Dis Child 1990;144: 1238-41.

9 Coster WJ, Haley S, Baryza MJ. Functional performance of young children after traumatic brain injury: a 6 month follow-up study. Am $\mathcal{F}$ Occup Ther 1994;48:211-8.

10 Sheeber LB, Johnson JH. Assessing families of difficult children. Psychol Rep 1992;71:155-9.

11 Northam E, Anderson P, Werther G, Adler R, Andrewes D. Neuropsychological complications of insulin dependent Neuropsychological complications of insulin depend
diabetes in children. Child Neuropsychol 1996;1:74-87.

12 Castles I. 1989-90 National health survey summary of results. Canberra: Australian Bureau of Statistics, 1991. (Catalogue No 4364.0.)

13 Nolan TM. Asthma. In: Pless IB, ed. The epidemiology of childhood disorders. Oxford: Oxford University Press, 1994: 415-38.

14 Robertson $\mathrm{CF}$, Williams $\mathrm{H}$ for The International Study of Asthma and Allergies in Childhood (ISAAC) Steering Committee. Worldwide variations in the prevalence of atopic dermatitis in children. Eur Respir $\mathcal{F}$ (in press).

15 Toelle BG, Peat JK, Mellis CM, Woolcock AJ. The cost of asthma to Australian families. Pediatr Pulmonol 1995;19: $330-5$. 